\title{
Heidegger e a ilusão transcendental
}

\section{Heidegger and the Transcendental Illusion}

\author{
RÓBSON RAMOS DOS REIS* \\ (Universidade Federal de Santa Maria)
}

\begin{abstract}
Resumo: Este artigo apresenta uma análise da abordagem de Heidegger à dialética transcendental no contexto de sua interpretação da Crítica da Razão Pura de Kant. Inicialmente, reconstruo a interpretação fenomenológica da Crítica da Razão Pura como sendo uma fundamentação da metafísica. A seguir, apresento a compreensão de Heidegger sobre o que ele chamou de significado positivo da dialética transcendental. O foco principal de sua interpretação é a noção de ilusão transcendental. Concluo este artigo examinando a noção de uma ilusão original, que Heidegger concebe como mais básica do que a ilusão transcendental examinada por Kant. Enfatizo que as subreções transcendentais que Kant explicou na dialética transcendental são interpretadas por Heidegger como casos particulares de uma confusão mais geral, cuja origem pertence à própria estrutura da compreensão do ser.

Palavras Chave: Heidegger, Kant, interpretação fenomenológica, dialética transcendental, ilusão transcendental
\end{abstract}

\begin{abstract}
This paper presents an analysis of Heidegger's approach to transcendental dialectics in the context of his interpretation of Kant's Critique of Pure Reason. Initially, I reconstruct the phenomenological interpretation of Critique of Pure Reason as being a foundation of metaphysics. Next, I present Heidegger's understanding of what he called the positive meaning of transcendental dialectics. The main focus of his interpretation is the notion of transcendental illusion. I conclude this paper by examining the notion of an original illusion, which Heidegger conceives as more basic than the transcendental illusion examined by Kant. I point out that the transcendental subreptions that Kant explained in the transcendental dialectic are interpreted by Heidegger as particular cases of a more general confusion, whose origin belongs to the very structure of the understanding of being.

Keywords: Heidegger, Kant, phenomenological interpretation, transcendental dialectic, transcendental illusion
\end{abstract}

O comentário dedicado por Heidegger à obra de Kant é conduzido pela interpretação da Crítica da Razão Pura como uma fundamentação da metafísica. Nos Conceitos Fundamentais da Metafísica vem à tona uma dimensão não evidente dessa interpretação. O problema da natureza indicativo-formal dos conceitos filosóficos é introduzido a partir do reconhecimento de uma característica atuante na compreensão de todos os problemas metafísicos. Essa característica teria sido examinada pela primeira vez na Dialética Transcendental. Os conceitos

\footnotetext{
* Este trabalho recebeu o apoio do $\mathrm{CNPq} /$ Brasil.
} 
metafísicos apresentam um erro necessário: a ilusão dialética. A ilusão transcendental não aniquila tais conceitos, mas implica a recorrência de problemas metafísicos. Apesar da importante elucidação da necessidade da metafísica, permanece a questão de se o problema da ilusão dialética teria sido desenvolvido por Kant de modo justificado e suficientemente radical. ${ }^{1}$ Tão importante quanto a análise de Kant é a existência de outra ilusão, qualificada por Heidegger como mais decisiva e mais originária do que a ilusão dialética. Esta ilusão originária também seria dotada de universalidade, pois se estabelece em todo pensamento filosófico. A ilusão originária está relacionada, por exemplo, com a desconsideração da natureza indicativoformal dos conceitos filosóficos. ${ }^{2}$

O tema da presente contribuição é a noção de uma ilusão mais originária do que a ilusão dialética. Considerarei inicialmente a abordagem da Dialética Transcendental no interior da interpretação heideggeriana da Crítica da Razão Pura. A seguir, reconstruirei a apresentação feita por Heidegger da noção de ilusão transcendental. Por fim, concluirei este trabalho analisando a noção de uma ilusão originária. Será evidenciado que as subrepções transcendentais analisadas por Kant na Dialética Transcendental são interpretadas por Heidegger como casos particulares de uma confusão mais geral, cuja origem é uma característica estrutural da compreensão de ser. Este resultado também é relevante para compreender a importância atribuída por Heidegger ao problema dos fundamentos do princípio de razão suficiente, pois a indiferenciação da compreensão de ser seria a origem da transformação do postulado lógico da razão no princípio transcendente da dadidade do incondicionado das séries condicionadas. Desta forma, a hipótese de que uma metafísica do seraí é a base para uma fundamentação da metafísica também elucida a origem necessária das ilusões metafísicas na finitude humana. Evidencia-se assim o contexto argumentativo desde o qual Heidegger identifica na própria filosofia transcendental de Kant a submissão a uma ilusão originária e necessária.

\section{A Crítica da Razão Pura como fundamentação da metafísica}

Heidegger insistiu na necessidade de se compreender o projeto transcendental da Crítica da Razão Pura como uma fundamentação da metafísica. Apoiando-se reiteradamente em uma passagem da carta a Markus Hertz, Heidegger ressaltava que o problema da possibilidade da metafísica é central na filosofia de Kant. ${ }^{3}$ Esta interpretação representou inicialmente uma diferenciação crítica em relação às interpretações desenvolvidas no neokantismo de Marburg, que entendia a Crítica da Razão Pura como uma epistemologia ou uma teoria do conhecimento das ciências matemáticas da natureza. ${ }^{4}$

A crítica de Heidegger à interpretação de Cohen e Natorp não permaneceu apenas no horizonte interpretativo geral, ao afirmar que a Crítica da Razão Pura não poderia ser entendida como a substituição critica da metafísica pela teoria do conhecimento. Ao conceber a pergunta pela possibilidade da experiência como uma investigação sobre a possibilidade de um conhecimento ontológico, Heidegger assinalava que o conhecimento sintético a priori precisava ser entendido como a exibição das determinações ontológicas dos entes representados com validade objetiva. Portanto, a fundamentação da metafísica significa inicialmente a elucidação das condições de uma ontologia geral dos entes como fenômenos, restringida ao campo mais limitado de uma lógica produtiva da natureza. ${ }^{5}$

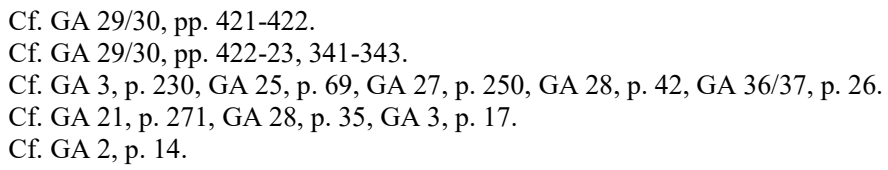


O problema da possibilidade do conhecimento sintético a priori encontrou o seu foco decisivo, segundo Heidegger, na questão da síntese da intuição segundo as regras a priori do entendimento. A necessidade da ligação entre entendimento e sensibilidade requeria uma estrutura intermediária, fornecida pelas determinações a priori do tempo na imaginação transcendental. A importância do esquematismo transcendental para a fundamentação da metafísica torna-se evidente. Do mesmo modo, a oposição de Heidegger ao idealismo lógico, que absorvia a Estética Transcendental na Analítica, não significava apenas a recusa de uma dedução do tempo a partir do pensamento puro. ${ }^{6}$ A irredutibilidade do tempo à atividade sintetizante do entendimento significava que o problema da unidade entre intuição e pensamento ainda permanece. Ora, se a unidade de ambas é possibilitada pela esquematização transcendental, entendida como condicionada pelo tempo em um sentido proeminente, então Heidegger encontra neste momento decisivo do projeto transcendental o apoio para a sua própria temática de interpretação da compreensão de ser a partir de uma temporalidade especial. Se o conhecimento sintético a priori é ontológico e possibilitado pela esquematização das categorias, então Kant estaria na direção de uma elaboração das condições temporais da transcendência. ${ }^{7}$

De outro lado, a elucidação da fundamentação da metafísica como uma tematização da temporalidade e da transcendência na compreensão de ser também é a ocasião para Heidegger acentuar um segundo aspecto da passagem da carta a Markus Hertz. Que a Crítica da Razão Pura seja uma 'metafísica da metafísica' também significa que a fundamentação da metafísica é ela mesma de natureza metafísica. $O$ vínculo entre fundamentação e crítica da razão determina ainda mais essa fundamentação metafísica. A possibilidade da metafísica é situada no contexto de uma crítica da razão humana finita, ou seja, numa tematização da subjetividade do sujeito humano. ${ }^{8}$ Heidegger identifica a formulação explícita deste vínculo entre fundamentação da metafísica e tematização da finitude na apresentação kantiana dos fins últimos da razão. Os fins últimos determinam a razão humana, exibindo a sua condição finita. Estes fins estariam presentes nas perguntas últimas a que tende a razão: o que posso saber? o que devo fazer? o que me é permitido esperar?' ${ }^{9}$ Os verbos modais 'poder', 'dever' e 'permitir' indicariam a finitude da razão.

Heidegger ressaltou inúmeras vezes o significado destas perguntas, na medida em que expressam os fins últimos da razão humana finita. ${ }^{10}$ Ele não deixou de se referir à passagem da introdução ao curso de lógica (Jäsche), na qual as três perguntas que expressam o objeto da filosofia em sentido cosmopolita são referidas por Kant à pergunta fundamental "o que é o homem?". No entendimento de Heidegger, a possibilidade de recondução das três perguntas à quarta questão significa que a fundamentação da metafísica deve ser buscada naquilo que é mais especificamente finito no ser humano: no ser-aí. Neste sentido, a metafísica da metafísica não pode repousar na antropologia, nem mesmo na antropologia filosófica, ${ }^{11}$ porque a fundamentação da metafísica não pode ser realizada por uma investigação científica positiva sobre o ser-humano. Nem mesmo uma fenomenologia da consciência e das vivências possibilita a elucidação do ser humano que é pertinente para a fundamentação da metafísica. Ela também precisa ser metafísica, e deve ser buscada numa metafísica do ser-aí. ${ }^{12}$

\footnotetext{
Cf. GA 21, p. 271.

Dahlstrom (1991, p 342) mostrou que a interpretação de Heidegger não se diferencia apenas do neokantismo de Marburg, mas também de aspectos centrais da fenomenologia de Husserl.

Cf. GA 3, p. 207.

Cf. A $805 /$ B 833 .

Cf. GA 3, 207-9, GA 25, p. 59, GA 28, pp. 36-37.

Cf. GA 28, p. 38, GA 3, pp. 213, 218, GA 31, p. 122.

Cf. GA 31, p. 205, GA 28, pp. 41, 234-235, GA 3, p. 230, GA 25, p. 71. Jaran, 2010 elucidou o projeto de uma metafísica do ser-aí, cuja culminância no conceito de liberdade acontece no período de 1926-30.
} 
A fundamentação da metafísica que Heidegger encontra na Crítica da Razão Pura aconteceria como uma investigação sobre a possibilidade interna da ontologia. ${ }^{13}$ Ela adquire a forma, portanto, de uma fundamentação da ontologia. Kant teria tomado o conceito tradicional de metafísica, entendida como metafísica geral e metafísica especial, examinando criticamente a possibilidade das duas grandes áreas da metafísica. Contudo, toda retomada genuína é também uma transformação. ${ }^{14}$ Com a filosofia transcendental teria ocorrido uma problematização e um abalo interno no edifício da metafísica herdada. ${ }^{15} \mathrm{O}$ questionamento kantiano pela possibilidade da metafísica como ontologia não seria antigo, mas algo "totalmente novo". ${ }^{16}$ Kant teria proporcionado uma nova e radical determinação da essência da ontologia, mas que, segundo Heidegger, não deixa de ser um aprofundamento renovado da pergunta antiga pelo ser. ${ }^{17}$

Em suma, para Heidegger a filosofia transcendental de Kant proporcionou uma fundamentação e transformação radical da metafísica no sentido de uma ontologia. Isto, porém, significa uma retomada do antigo questionamento do ser. ${ }^{18}$ A ontologia como filosofia transcendental significa, portanto, uma elucidação dos princípios dos objetos que podem ser dados na experiência possível. Heidegger é plenamente ciente da mudança radical que está assinalada em tal concepção da metafísica geral. E ele não poderia deixar sem comentário a grave declaração de Kant, segundo a qual os princípios do entendimento são apenas regras de exposição dos fenômenos, "devendo o soberbo nome de ontologia - a qual se arroga o direito de fornecer em uma doutrina sistemática conhecimentos sintéticos a priori sobre coisas em geral (...) - ceder lugar ao modesto nome de uma simples analítica do entendimento puro.” (B 303)

No Kantbuch Heidegger citou explicitamente esta passagem, sustentando que nela a expressão ontologia é empregada por Kant na acepção tradicional. ${ }^{19}$ A soberba e a arrogância da ontologia herdada residiriam na pretensão de oferecer conhecimentos sintéticos necessários e universais sobre coisas em geral, ou seja, sobre coisas em si mesmas. Segundo Heidegger, o conceito de coisa em si refere-se às coisas não em relação a um ente finito determinado por uma receptividade sensível, mas às coisas independentemente desta relação e em relação a um possível ente infinito. Neste sentido, a ontologia em sentido tradicional presume ser capaz de um conhecimento que é possível apenas para um ente infinito. Na medida em que a ontologia, transformada em filosofia transcendental, abandona esta soberba, ela se compreende em sua finitude. Assim, haveria um sentido legítimo para a expressão ontologia, precisamente quando ela é transformada e fundamentada na filosofia transcendental. Além disso, Kant também teria empregado a expressão com este novo significado, ao expor o plano geral da metafísica numa passagem decisiva da Crítica. ${ }^{20}$

Em suma, a unidade da Estética Transcendental e da Analítica Transcendental forneceria, segundo Heidegger, uma fundamentação da metafísica, entendida a partir da noção de metaphysica generalis. Com esta transformação da metafísica geral todo alicerce da metafísica tradicional é posto em movimento e, portanto, a metaphysica specialis é afetada como um todo. No Kantbuch Heidegger não avançou para além dessa afirmação, justificando a restrição com a

\footnotetext{
Cf. GA 25, pp. 59, 61, 63-4, 66, GA 27, pp. 249-50, 256-57, GA 3, p. 16.

Cf. GA 27, pp. 249-250.

Cf. GA 3, p. 12.

Cf. GA 25, p. 67.

Cf. GA 31, p. 203.

8 Referindo-se a B 845, Heidegger observa que a expressão objeto em geral não significa em Kant o algo formal em geral, pois Kant não teria conhecido a ontologia formal no sentido de Husserl (GA 25, p. 64).

19 No seu artigo sobre o comentário de Heidegger a Kant, Dahlstrom observou criticamente que Heidegger não considerou a passagem em B303 (1987, p. 356). Loparic também declarou criticamente que Heidegger nunca citou a referida passagem da primeira Crítica (2009, p. 516). Contrariamente as duas afirmações, Heidegger de fato citou e comentou no Kantbuch a passagem de B303 (Cf. GA 3, p 124). A identificação heideggeriana da filosofia transcendental com a ontologia também foi objetada por Macann, 1996, pp. 110-111.

20 Cf. GA 3, pp. 124-25, em que Heidegger se refere a KrV A845/B873.
} 
observação de que o tratamento do problema requer uma preparação obtida apenas com a apropriação originária da fundamentação kantiana da metafísica geral. ${ }^{21}$

Contudo, sem o desenvolvimento deste tema não é possível avançar no exame da tese de uma ilusão mais originária do que a ilusão dialética. Assim sendo, se a Crítica obtém um resultado negativo para as pretensões da metaphysica specialis, de que modo a interpretação da filosofia transcendental teórica como uma fundamentação da metafísica pode acomodar este resultado? A fundamentação e transformação radical da metafísica significam a restrição ao plano de uma ontologia geral dos objetos da experiência possível? Em termos mais gerais: qual o tratamento oferecido por Heidegger para a Dialética Transcendental?

\section{A fundamentação da metafísica e a Dialética Transcendental}

É notório que da Dialética Transcendental não resulta apenas a negação da possibilidade de juízos sintéticos a priori nas metafísicas transcendentes. Kant também expôs em detalhe o surgimento da metafísica a partir de uma ilusão necessária com sede na própria razão. $\mathrm{O}$ uso puro da razão, que conduz a três classes de conceitos que contém a noção de uma totalidade absolutamente incondicionada, pode ser vítima de uma ilusão não contingente. Quando a necessidade subjetiva de uma conexão conceitual favorável ao uso continuado e unificado do entendimento é tomada por uma necessidade objetiva da determinação das coisas como tais, ocorre um erro que conduz a um uso constitutivo das idéias. ${ }^{22}$ Este uso proporciona o surgimento de problemas e inferências da razão, cujo erro pode ser identificado pela reflexão transcendental. Uma dupla subrepção transcendental afeta o postulado lógico que expressa analiticamente a relação entre algo condicionado e o regresso à sua condição. Caso se desconsidere o modo de ser das coisas condicionadas, então ocorre a confusão das determinações de fenômenos como determinações de coisas em si mesmas. Além disso, do fato empírico do estar dado de algo condicionado é assumido o fado do estar dado de sua condição e, portanto, de toda a série. Ao apontar o idealismo transcendental como a chave para solucionar criticamente os problemas da razão, Kant não apenas elimina a metafísica transcendente, mas analisa a origem de argumentos e proposições transcendentes a partir de uma ilusão própria da razão. A limitação no domínio especulativo garante a possibilidade de uma ampliação da razão no domínio prático. O interesse humano por estes objetos meramente pensáveis é preservado e as perdas resultantes da crítica atingem apenas as escolas.

$\mathrm{Na}$ interpretação da obra de Kant elaborada por Heidegger não há uma exposição concentrada e sistemática da Dialética Transcendental. $\mathrm{O}$ foco da atenção recai na doutrina da temporalidade e do esquematismo, entendidos como o campo próprio da fundamentação kantiana da ontologia. No Kantbuch na há um exame da Dialética, e nos cursos com partes dedicadas à filosofia kantiana encontram-se passagens relacionadas à doutrina kantiana da existência como posição absoluta, à doutrina da personalidade (transcendental, empírica e moral), bem como ao conceito de mundo e ao tema das antinomias (com um foco na terceira antinomia da causalidade e da liberdade transcendental). Contudo, as observações de Heidegger sobre a Dialética, que estão registradas nos seus cursos, oferecem um material suficiente para uma reconstrução que possibilite o entendimento da afirmação de uma ilusão mais originária do que a ilusão dialética. ${ }^{23}$

\footnotetext{
Cf. GA 3, p. 125.

Cf. A297/B353-354

Para um detalhamento do comentário de Heidegger a Crítica da Razão Pura, ver o levantamento apresentado por Dahlstrom, 1989a, pp. 365-366: ver também Dahlstrom, 1989b e 1991. Talvez a falta de uma análise sistemática da Dialética Transcendental seja um dos motivos da pouca atenção dedicada ao tema na literatura. As observações de Sherover, 1971, pp. 49, 59 sobre Heidegger não ver a necessidade de analisar a Dialética são restringidas pelos
} 
Para Heidegger, a pergunta kantiana pela possibilidade da metafísica toma da tradição um conceito de metafísica estruturado em duas partes - metaphysica generalis e metaphysica specialis. A metafísica propriamente dita seria a metafísica especial, orientada para um conhecimento racional de três domínios ônticos suprasensíveis (Deus, alma e mundo). Ao assumir esta idéia tradicional, Kant estaria preocupado em responder expressamente a pergunta pela possibilidade da metafísica. Esta questão seria dupla e Kant não teria em vista um destroçamento da metafísica, mas a sua investigação orienta-se inclusive para a fundamentação da metafísica especial. É digno de nota que Heidegger interprete as três perguntas fundamentais da razão humana como sendo as perguntas das três metafísicas especiais. ${ }^{24}$ Assim, também na Dialética Transcendental estaria em curso uma fundamentação da metafísica. A fundamentação da metafísica especial é feita a partir de uma fundamentação da sua propedêutica, a metafísica geral.

No entanto, a pergunta pela possibilidade da metafísica traça limites, o que significa o sentido crítico da fundamentação. Perguntar pela essência da metafísica implica, portanto, delimitar aquilo que não lhe pertence, isto é, o que a razão é capaz em relação ao conhecimento dos entes. ${ }^{25}$ Heidegger não ignora que a Dialética Transcendental tem um sentido negativo para a metafísica especial. Uma ciência teórica do suprasensível é impossível, e Heidegger acrescenta:

Por isso a fundamentação da metafísica como ciência não é apenas fundamentação em geral $d a$ filosofia transcendental ou ontologia, mas também circunscrição e delimitação do possível conhecimento a priori da razão pura, isto é, crítica. (GA 25, p. 61).

Segundo Heidegger, o resultado da Crítica da Razão Pura até o início da Dialética transcendental é que não é possível um conhecimento ontológico que faria acessível o ente suprasensível, ou seja, não há conhecimento ôntico a priori. O conhecimento a priori possível na metafísica é ontológico, isto é, na metafísica geral como filosofia transcendental. ${ }^{26} \mathrm{Na}$ mesma passagem citada Heidegger também registra que este resultado negativo possui uma função positiva no tocante à elaboração de uma metafísica prático-dogmática. Esta interpretação não possui nada de incomum e poderia explicar também porque a compreensão da Crítica da Razão Pura como uma fundamentação da metafísica estaria concentrada apenas na Estética e na Analítica Transcendental. A fundamentação e transformação da ontologia significariam a redução da metafísica com a exclusão da metafísica especial do domínio do conhecimento teórico. Contudo, Heidegger faz uma observação central que coloca sob nova perspectiva o sentido da Dialética Transcendental. Também a relação entre metafísica geral e metafísica especial é vista sob outro aspecto, implicando uma importante qualificação na noção de fundamentação da metafísica. No curso de inverno de 1927/28 ele afirma:

A parte positiva da Lógica Transcendental consiste, portanto, na Analítica Transcendental. Certamente também pode ser fornecido um sentido positivo para a Dialética Transcendental, o que, segundo minha opinião, nunca aconteceu até agora. A pressuposição para isso é, no entanto, que se compreenda corretamente a intenção fundamental da "Crítica" - a fundamentação da metafísica. Então se pode mostrar que - e queremos tentar a prova - a Dialética Transcendental não é outra coisa do que uma interpretação ontológica da metafisica natural, i.e., da estrutura fundamental do que chamamos de a visão de mundo natural do homem. (GA 25, p. 196.)

comentários disseminados ao longo dos cursos do final dos anos vinte. Schalow dedicou um trabalho ao diálogo Heidegger-Kant sob o ângulo da Dialética Transcendental (1987), apesar do artigo não oferecer uma reconstrução detalhada das observações de Heidegger sobre temas da Dialética.

24 Cf. GA 28, p. 36. Sobre a estruturação tradicional da metafísica e a relação entre metafísica geral e especial, cf. GA 27, pp. 249, 256, GA 3, p. 11, GA 28, p. 37, GA 31, p. 204.

25 Cf. GA 31, p. 204.

26 Cf. GA 27, p. 276. 
A observação é muito significativa, pois afirma um sentido positivo para a Dialética. A crítica da ilusão transcendental não esgota o sentido global desta parte da Crítica. No entanto, a obtenção deste sentido positivo ainda não teria sido realizada e dependeria de uma correta compreensão da idéia de fundamentação da metafísica. Portanto, a interpretação heideggeriana da Crítica contempla uma compreensão da Dialética não apenas em sentido crítico-limitativo. O sentido positivo da Dialética é formulado em quatro momentos: 1) ela é uma interpretação ontológica; 2) é uma interpretação da metafísica natural, 3) a metafísica natural é a visão natural de mundo do ser humano (die natürliche Weltanschauung des Menschen), e 4) a interpretação ontológica visa à estrutura fundamental da referida visão de mundo. É relevante que Heidegger tenha destacado como sendo a sua intenção oferecer uma prova desta interpretação. Isto implica que a sua interpretação geral da Crítica da Razão Pura deveria ir além de uma exposição destrutiva da doutrina do esquematismo e da temporalidade.

Como já ressaltei, desconheço se uma exposição sistemática desta interpretação e sua demonstração foram elaboradas por Heidegger. A abordagem do conceito de ilusão no presente artigo representa apenas um passo preparatório para uma tentativa de seguir as indicações fornecidas por Heidegger em relação aos quatro pontos acima destacados. Não posso elaborar aqui o ponto 3, que abrange o problema mais geral da Weltanschauung ao longo da obra de Heidegger. ${ }^{27}$ Observo apenas que a equiparação entre metafísica e Weltanschauung implica que a idéia de metafísica considerada por Kant é vista como dependente dos elementos formadores de uma visão de mundo, introduzindo, portanto, um componente não apenas destrutivo na interpretação heideggeriana de Kant. Neste caso, a noção de formação de mundo é que entra no foco da interpretação ontológica. Em relação ao ponto 2, Heidegger observou que a expressão metaphysica naturalis foi empregada por Baumgarten e pode ser identificada na concepção kantiana da metafísica como uma disposição natural (Naturanlage). ${ }^{28} \mathrm{O}$ sentido positivo da Dialética refere-se, portanto, à metafísica como originada da natureza e do interesse mais geral dos seres humanos. Neste sentido, a necessidade da ilusão transcendental é o ponto central para examinar a origem da metafísica. Por fim, uma interpretação ontológica significa, de um lado, uma investigação sobre estruturas e, de outro, uma interpretação que deve se remontar às estruturas ontológicas presentes na compreensão de ser. Não se trata, portanto, nem de uma antropologia, uma psicologia ou etnologia da gênese da metafísica e das visões de mundo, mas de uma metafísica do ser-aí que exiba os fundamentos da metafísica a partir da finitude da temporalidade e da compreensão de ser.

Um ano após o curso sobre a Crítica da Razão Pura, Heidegger retoma a perspectiva de um sentido positivo na Dialética Transcendental. Ao afirmar que na ilusão transcendental é preciso ver algo positivo, ele ressalta que Kant empreendeu o trabalho limitativo a partir dos resultados da Analítica, mostrando que as pretensões de conhecimento ôntico-apriorístico sobre Deus, mundo e alma não podem ser satisfeitas. Contudo, diz Heidegger, não se trata apenas de rejeitar esse conhecimento,

mas antes de mostrar positivamente a legitimidade desse intuito cognitivo em vista da natureza do homem, ao qual pertence esse perguntar. Não devemos apenas reconhecer a ilusão desse conhecimento ôntico-apriorístico, mas precisamos ter clareza quanto ao seguinte fato: onde há aparência - aparência (Schein) como ilusão (Illusion) natural necessária - aí também está a verdade. (GA 27, p. 276)

É pertinente ressaltar inicialmente que Heidegger não afirma que o conhecimento transcendente na metafísica especial seja objeto de uma legitimação positiva. Há ilusão e erro na metafísica especial. A legitimação em questão diz respeito ao intuito cognitivo

\footnotetext{
27 Cf. Müller, 2010.

28 Cf. GA 25, p. 60 e Kant, B22.
} 
(Erkenntnisabsicht) presente na metafísica especial. Tal intenção cognitiva relaciona-se com os fins e interesses últimos da razão humana finita, entre os quais o interesse prático tem sua preponderância reconhecida por Kant. Heidegger observa criticamente que Kant não formulou o problema do conhecimento ontológico na amplitude total da compreensão de ser.

Um comentário adicional também avança na qualificação do sentido positivo da Dialética. Para Heidegger, Kant não simplesmente aplicou os resultados da Analítica no problema da possibilidade da metafísica especial. Ao contrário, a Dialética exibiria o verdadeiro fundamento do ponto de partida. O tópico não é desenvolvido, mas significa que o sentido positivo da Dialética alcança também as bases mais fundamentais da própria ontologia transformada em filosofia transcendental. Heidegger observa que a dificuldade em compreender o projeto de uma fundamentação da metaphysica specialis e sobretudo da sua relação com a metafísica geral resulta da arquitetônica da Crítica. A arquitetônica não seria apenas uma questão de disposição externa, mas refere-se ao primado da lógica no conjunto da obra kantiana e, em última instância, na história da metafísica como um todo. A primazia não esclarecida e não questionada da lógica fez com que a passagem para a fundamentação da metafísica especial ganhasse um aspecto violento e artificial. ${ }^{29}$

Esta observação sobre a arquitetônica e o primado da lógica também aparece num contexto central, ao final de Kant e o Problema da Metafísica. Heidegger observa que a sua interpretação da Crítica orientada na ontologia fundamental aprofundou a questão da fundamentação da metafísica, mas se detivera diante do decisivo. A orientação na possível continuidade da investigação é oferecida por meio de uma série de perguntas. Estas questões indicam de modo interrogativo o sentido positivo da Dialética Transcendental. Apesar de aparentar ser apenas a aplicação crítica da compreensão obtida acerca da metafísica geral, recusando a possibilidade de uma metafísica especial, na Dialética haveria uma problemática positiva. Esta problemática seria a da finitude do ser-aí. Heidegger adverte que este tema conduziu de modo não elaborado e oculto toda a discussão da fundamentação da metafísica. Ele é enfático ao sugerir que o problema da finitude está relacionado com a Dialética Transcendental e com a noção de ilusão transcendental:

Kant diz que a 'ilusão transcendental', à qual se deve a possibilidade da metafísica tradicional, é uma ilusão necessária. Esta não-verdade transcendental não precisa ser justificada positivamente, no tocante a sua unidade originária com a verdade transcendental, a partir da essência mais interna da finitude no ser-aí? À essência desta finitude pertence a não-essência (Unwesen) daquela ilusão? (GA 3, p. 245.)

$\mathrm{Na}$ próxima seção abordarei a interpretação heideggeriana da noção kantiana de ilusão transcendental. É importante observar agora que o sentido positivo da Dialética Transcendental é identificado no problema da finitude do ser-aí. Heidegger encontra uma indicação desta tese interpretativa na observação de Kant à solução dos problemas antinômicos da razão pura, de acordo com o qual a solução da antitética seria uma prova indireta da verdade do idealismo transcendental e da distinção entre fenômeno e coisa em si. ${ }^{30}$ A solução do conflito antinômico provaria indiretamente a distinção fenômeno e coisa em si. Ao considerar esta distinção como expressando a diferença entre conhecimento finito e conhecimento infinito, Heidegger conclui que na Estética, na Analítica e na Dialética Transcendental o tema da finitude do ser humano seria a base condutora da delimitação da metafísica geral e também da metafísica especial. E ele acrescenta:

29 Cf. GA 27, pp. 277-278. Schalow, 1994, não examinou o papel da lógica na interpretação heideggeriana da Dialética Transcendental. Não encontrei algum documento que justificasse a atribuição da "tirania da lógica" ao aparecimento e colapso da metafísica (Schalow, 1987, p. 199).

30 Cf. B 534

Studia Heideggeriana, Vol. I, 2020, $2^{\mathrm{a}}$ ed. 
A finitude do homem não foi tematizada de modo decidido e desde o seu fundamento tendo como propósito o problema geral de uma fundamentação da metafísica e dentro dos limites de tal problema. Por exemplo, na doutrina da antinomia Kant contenta-se com a exibição do conflito, com a sua dissolução e, deste modo, com a indicação da ilusão natural que jaz na natureza do homem, o que era adequado para os seus fins imediatos. (GA 31, 235)

Em resumo, Heidegger considera que a Dialética Transcendental possui um sentido positivo, apesar de não ter apresentado esta tese em um desenvolvimento sistemático. O significado positivo, que não anula os resultados críticos em relação à metafísica transcendente, está relacionado com o problema da finitude humana. A finitude que se apresenta na forma de uma ilusão necessária que, por sua vez, revela a metafísica como uma disposição igualmente necessária da natureza humana.

\section{A ilusão transcendental}

Heidegger insiste repetidamente na afirmação kantiana sobre a disposição natural do ser humano para a metafísica. Kant não pode justificar tal asserção sem fazer uma consideração sobre a natureza humana. Esta é uma situação incômoda para a interpretação de Kant, diz Heidegger, mas não há como negar o fato que a fundamentação da metafísica precisa ser feita através de uma referência à natureza humana. Neste sentido, a correção da justificação depende da originariedade, adequação e completude da interpretação kantiana do ser humano. ${ }^{31}$

Também é um foco recorrente no comentário de Heidegger a afirmação kantiana sobre a existência de uma ilusão necessária situada na própria razão, a partir da qual a metafísica surge como uma disposição natural. Em inúmeras passagens da Crítica da Razão Pura Kant ressalta que a ilusão transcendental não é arbitrária, nem pode ser eliminada. Para Heidegger, isso é fundamental. No anexo IV de Kant e o Problema da Metafísica, que contém a transcrição do debate entre Cassirer e Heidegger, há um pronunciamento contundente neste sentido. Após afirmar que Kant não pretendia oferecer uma teoria da ciência natural, mas sim exibir a metafísica como ontologia, Heidegger afirma que:

Com base na minha interpretação da Dialética como ontologia acredito poder mostrar que o problema
da ilusão na Lógica Transcendental, que aparentemente se apresenta em Kant apenas negativamente,
é um problema positivo, de tal forma que é possível perguntar: a ilusão é apenas um fato que
constatamos ou o problema total da razão precisa ser concebido de um modo tal que se conceba de
antemão como a ilusão pertence necessariamente à natureza do homem. (GA 3, p. 275)

Portanto, a centralidade da Dialética e do conceito de ilusão transcendental é evidente. A ilusão transcendental tem o seu lugar na própria razão. Para analisar o conceito de ilusão Heidegger toma por base a noção de ideia. ${ }^{32}$ A razão é capaz de formar uma classe especial de representações, as idéias. Ao transformar um juízo analítico em um princípio sintético, que enuncia não apenas a relação entre condicionado e condição, mas estabelece que esteja dada a série incondicionada para um condicionado dado, a razão gera um tipo de representação que visa totalidades incondicionadas absolutas. Tais representações não se referem a totalidades capazes de ser dadas em alguma experiência possível, mas possuem a função de promover uma unidade maximal no uso empírico do entendimento. De acordo com Heidegger:

Cf. GA 31, pp. 204-205.

Esta apresentação do comentário de Heidegger sobre a noção de ideia tem por base os textos dedicados ao problema em GA 27, pp. 279-288 e GA 31, 206-208. 
(...) a ideia é uma representação conceitual apriorística da totalidade absoluta, uma representação que prescreve uma direção e é impossível de ser satisfeita por meio da intuição; uma representação que dá uma unidade à síntese do entendimento como tal e funciona como um fundamento da síntese do condicionado, isto é, uma representação conceitual, transcendentalmente real do incondicionado. (GA 27, p. 285)

Portanto, a razão visa com suas ideias a representação da totalidade, unidade e completude do representável. ${ }^{33}$ Incapazes de uma dedução objetiva, as ideias admitem apenas uma derivação subjetiva. Esta derivação é ambígua. De um lado, por referência ao tipo de relação expressa na premissa maior dos silogismos; de outro, segundo as três direções em que as representações humanas admitem séries generalizáveis: o universal na relação da representação com o sujeito, com os fenômenos, e com as coisas em geral. ${ }^{34}$ Contudo, as ideias da unidade incondicionada do sujeito pensante, da unidade incondicionada da série dos fenômenos e da unidade absoluta das condições dos objetos do pensamento não proporcionam a partir de si mesmas o aparecimento dos problemas metafísicos da razão. Em seu uso regulativo, que oferece uma regra da máxima ampliação e unidade no conhecimento dos objetos da experiência, a razão não está sob a ilusão. ${ }^{35}$ Portanto, é apenas a partir de um certo uso das ideias que surgem os problemas metafísicos. Este uso é originado da ilusão transcendental. De acordo com Kant (citado por Heidegger em Ser e Tempo, GA 2, p. 285), a ilusão é um erro que está no pensamento dos objetos e não nos objetos. As ideias não podem receber uma dedução objetiva, isto é, falta-lhes a comprovação da sua correção através de uma intuição. ${ }^{36}$ Assim sendo, a ilusão transcendental é apresentada por Heidegger como uma ação do entendimento em relação a essa falta da possibilidade de prova na experiência:

Falta esta possibilidade de comprovação. No entanto, o entendimento não vê esta falta, nem toma como necessária a comprovação. Ao contrário, ele a considera como já tendo sido empreendida em função do a priori. Assim, ele decai em uma ilusão. (GA 29/30, p. 422).

A ilusão acontece com o entendimento, que não reconhece a ausência de justificação das ideias, ou melhor, quando toma por desnecessária uma prova das ideias. A estrutura formal da ilusão aparece: tomar algo por algo que não é. Neste caso, tomar como já ocorrida uma justificação que ainda não foi e nem poderá ser feita. Heidegger não desenvolve a afirmação que relaciona com o a priori a consideração das ideias como já tendo sido comprovadas. É em função do a priori (aufgrund des a priori) que o entendimento considera como já feita a comprovação das ideias. O ponto é central não apenas para o conceito de ilusão, mas especialmente para o problema da origem da ilusão necessária. Uma passagem do curso inverno de 1928/29 oferece elementos para desenvolver o tópico. Heidegger diferencia entre conhecimento ôntico a priori (aquele pretendido na metaphysica specialis) e o conhecimento ontológico (aquele que torna possível os juízos sintéticos a priori, e que seria deduzido na filosofia transcendental como ontologia). Depois de explicitar a noção de ilusão transcendental dizendo que nela algo se apresenta como conhecimento ôntico a priori, mas não o é, Heidegger inicia o Excurso sobre a dialética kantiana nos seguintes termos:

Para que possamos discutir a sede da ilusão e da ilusão transcendental em geral não carecemos apenas da analítica precedente. $\mathrm{Na}$ ilusão mesma reside algo positivo que se apresenta como... e não é idêntico aos conhecimentos sintéticos a priori, mas se acha mesmo à base desses conhecimentos como sua condição de possibilidade... A verdadeira problemática

\section{Cf. GA 31, pp. 206-207.}

34 Cf. GA 27, p. 288. Heidegger toma por base apenas a segunda derivação das ideias que Kant fornece em A333/B390-1. Cf. GA 27, p. 283, GA 9, p. 150, GA 31, p. 207.

35 Cf. GA 31, p. 240.

36 Desconheço se Heidegger tematizou alguma vez o problema do esquematismo simbólico ou analógico das ideias da razão. 
ontológica central atinge o ideal transcendental, isto é, ela emerge daí, ou seja, da essência da razão humana finita, ‘... desse homem divino em nós...' (A569/B597).” (GA 27, p. 275-276)

Também aqui vemos a mesma estrutura ilusória que consiste em confundir conhecimento ôntico $a$ priori com conhecimento ontológico. A metafísica transcendente é definida exatamente nestes termos: "metaphysica specialis: uma ilusão necessária - uso transcendental, isto é, tomar o ontológico como ôntico". (GA 28, p. 31 n12)

Assim sendo, na ilusão não há apenas erro, mas também há uma positividade: algo se apresenta apesar de se mostrar tal como não é. No presente caso, a confusão é entre um conhecimento sintético a priori com as suas condições de possibilidade. Na metafísica especial buscam-se conhecimentos sintéticos a priori sobre algo que não pode ser dado na experiência possível. No entanto, o que está se mostrando, mesmo que na forma da ilusão, são as condições de possibilidade do conhecimento sintético a priori. O que está na base de tal conhecimento é a apercepção transcendental, a sensibilização das categorias do entendimento através da esquematização, e espaço e tempo como formas da intuição das coisas enquanto fenômenos, ou seja, o que Heidegger simplificadamente chamou de "o apriori".

Na ilusão transcendental acontece uma confusão entre o que é condição de possibilidade das coisas enquanto fenômenos com as determinações das coisas em geral, das coisas pensadas em si mesmas. A crítica empreendida na Dialética Transcendental permite reconhecer a confusão que reside, por exemplo, em tomar uma conexão subjetivamente necessária por uma necessidade objetiva das coisas, em tomar o que qualifica apenas fenômenos por determinações de coisas em geral, enfim, confundir fenômeno e coisa em si. No entanto, a confusão mostra-se positivamente na ilusão. A Dialética revela a positividade da ilusão, isto é, a ilusão exibe um traço essencial da razão finita humana.

Permanecem ainda dois problemas para o entendimento das duas passagens antes citadas: como o elemento positivo que se mostra na ilusão relaciona-se com o problema do ideal transcendental? E por que o a priori é a razão explicativa daquele aspecto da ilusão transcendental que consiste em tomar como já empreendida e desnecessária a comprovação das ideias da razão? O primeiro problema é difícil, porque Heidegger não ofereceu nenhum comentário adicional sobre a passagem citada. ${ }^{37} \mathrm{O}$ segundo caso admite um comentário. Podese cogitar que, a despeito da honrosa vantagem que representa, a prova da validade objetiva das condições da representação de objetos é uma exigência apenas para investigação transcendental. ${ }^{38}$ Deste modo, o uso simplesmente empírico do entendimento concede para este mesmo entendimento a evidência de que uma prova das condições de possibilidade de tal uso empírico é desnecessária.

A observação precedente considera a diferença entre reflexão transcendental e o uso empírico do entendimento como explicativa da submissão do entendimento à ilusão transcendental (no aspecto de tomar como já empreendida a comprovação das ideias). No entanto, esta não é uma formulação que encontramos explicitamente nas observações de Heidegger. Assim, é recomendável examinar mais detalhadamente a análise da ilusão transcendental nas inferências dialéticas da razão. Neste caso, não apenas há um detalhamento maior da noção, mas Heidegger pretende ter chegado ao solo profundo no qual se enraíza a ilusão transcendental.

37 Heidegger considerou a relação entre o ideal pertencente à essência do homem (tomado como ser prático) e o ideal transcendental especulativo (cf. GA 27, pp. 290-295). De outro lado, uma indicação que permite desenvolver o tema reside na afirmação que somente no problema do ideal o problema do mundo encontra o seu lugar sistemático. Cf. GA 9, p. 152, GA 27, pp. 391-392.

38 Cf. B 296-297 


\section{A ilusão transcendental, a razão comum e a compreensão de ser}

O foco principal da análise de Heidegger na abordagem dos paralogismos não é a ilusão transcendental, mas a doutrina kantiana da personalidade. Não obstante, nessa interpretação também é analisada a ilusão das inferências paralogísticas, que é dupla. ${ }^{39}$ A primeira é uma confusão entre condição e condicionado. O 'eu penso', enquanto condição das formas da vinculação sintetizante (as categorias), não pode ser determinado por estas mesmas categorias. A segunda falha reside numa subrepção originada do fato de haver consciência, mas não experiência do sujeito transcendental. O sujeito na apercepção transcendental não é afecção, mas espontaneidade, função e ação. Portanto, o eu da apercepção não é acessível para uma determinação categorial. Quando a determinação categorial é feita, então acontece uma subreptio appercetionis substantiae. O esquema é a figurae dictionis na qual um ente é pensado em geral e também como pode ser dado, mas na premissa menor é tomado como sujeito apenas em relação ao pensamento e à unidade da consciência, portanto, não em relação com a intuição. A confusão reside em tomar a exposição lógica do pensamento por uma determinação metafísica do objeto.

Na reconstrução das falhas nas inferências paralogísticas está presente a confusão constante na ilusão transcendental: tomar determinações de objetos enquanto fenômenos como sendo das coisas em geral. Ao se tomar o sujeito meramente lógico do juízo como uma coisa em si capaz de categorialização, procede-se a aplicação de categorias que somente adquirem sentido caso sejam sensibilizadas pela afecção de algo, o que não é o caso para o eu da apercepção. No exame do problema do ideal, contudo, Heidegger avança mais na análise da ilusão transcendental.

$\mathrm{O}$ problema do ideal surge de uma ilusão relacionada com a noção de coisa em geral. Na medida em que o conceito de coisa está relacionado com o principio da determinação completa - omnitudo realitatis - então a própria noção de coisa supõe a ideia do conjunto da inteira possibilidade. O princípio da determinação completa pressupõe a idéia de um conjunto de todos os predicados possíveis. Quando esta idéia é realizada e hipostasiada chega-se ao conceito de ens realissimum. Heidegger examina as passagens da Crítica referentes à ilusão que dá origem ao ideal, destacando que ela repousa na confusão entre princípios que valem dos fenômenos com princípios que valem de coisas em geral. De acordo com Kant, os objetos dos sentidos são dados no contexto da experiência possível. Portanto, algo somente é objeto caso seja pressuposto o conjunto da realidade empírica. Acontece a ilusão, quando um princípio válido dos objetos dos sentidos é tomado como válido para coisas em geral. O princípio empírico da possibilidade ligada aos fenômenos é tomado como sendo um princípio transcendental das coisas em si mesmas. ${ }^{40}$

A abordagem dos problemas cosmológicos da razão é feita por Heidegger no contexto do problema da liberdade, que se localiza no centro da metafísica do ser-aí. Heidegger formula a hipótese da dupla via que conduz ao problema da liberdade: a cosmológica e a moral. Kant estaria preso à tradição metafísica ocidental, pois formula o conceito de liberdade a partir da noção de causalidade. No final do curso de verão de 1930, Heidegger afirma uma tese fundamental segundo a qual a causalidade se funda na liberdade, o que mostraria a questão da essência da liberdade como o problema fundamental da filosofia. ${ }^{41}$ A despeito da relevância do tema, importa destacar agora como a elucidação da ilusão transcendental cosmológica chega à noção de razão comum humana.

\footnotetext{
Cf. GA 24, pp. 204-205.

Cf. GA 27, p. 295 e A 582 / B 610.

Cf. GA 31, p. 303.
} 
Heidegger examina em detalhe a análise kantiana do procedimento da razão que conduz da liberação dos limites do entendimento aos problemas cosmológicos. ${ }^{42} \mathrm{O}$ ponto central reside no princípio da razão: se o condicionado está dado, está dada a sua condição e a série completa das condições. Sobre este princípio opera o engano, porque nele se enuncia a relação entre condição e condicionado, mas também a relação entre o estar dado das condições e o estar dado do condicionado.

A ilusão acontece no uso confuso de um princípio legítimo. A primeira confusão consiste em tomar uma relação lógico-conceitual apenas pensada por uma relação fáctico-ôntica capaz de ser dada no acontecer temporal da experiência. O princípio da razão é um postulado lógico. Nele se enuncia a relação entre o conceito de condicionado e o regresso à sua condição. A relação é puramente pensada, e o regresso é uma tarefa imposta. Neste sentido inobjetável do postulado não se enuncia nada sobre a relação entre a dadidade (Gegebenheit) do condicionado e a dadidade das condições. O postulado adquire outro significado quando é expressa a relação entre a dadidade do condicionado e das condições. ${ }^{43}$

A confusão operada no princípio da razão vai adiante, atingindo o modo de ser daquilo que é dado como condicionado. No uso comum do princípio da razão o condicionado é tomado como uma coisa em si, sem uma qualificação sobre o que, quando, e como está dado. Neste caso, impõe-se a relação simplesmente pensada entre condicionado dado e a série dada e total de suas condições. Quando não se considera que o condicionado é um fenômeno dado na experiência, e que o regresso às suas condições precisa ser empreendido de modo sucessivo no tempo, então é possível concluir pela concomitante dadidade de condição e condicionado. Quando se toma o condicionado como dado na experiência, então a dadidade de suas condições precisa ser obtida pelo regresso efetivamente buscado no tempo. Ao apresentar sinteticamente a figurae dictionis que opera no silogismo hipotético das quatro antinomias, Heidegger resume nos seguintes termos a confusão no uso comum do postulado lógico:

Inicialmente a razão comum equipara a evidência da relação conceitual puramente ontológica com a relação ôntica do estar dado de condicionado essente e condição essente. O ente é tomado aqui como coisa em si, isto é, sem considerar as condições de sua possível dadidade. (GA 31, p. 232)

Portanto, Heidegger reconhece na ilusão transcendental a presença de duas confusões em relação ao postulado lógico da razão: a subrepção do modo do estar dado e a subrepção do modo de ser. ${ }^{44}$ A razão comum move-se numa ilusão completamente natural. Quando a reflexão analisa as confusões no princípio da razão, o conflito desaparece. A diferença entre fenômeno e coisa em si exibe uma aparente oposição analítica com sendo uma oposição dialética, eliminando a contradição antinômica.

A raiz da ilusão transcendental, segundo a interpretação de Heidegger, repousa na razão comum (gemeine Vernunft). O comum da razão reside na indistinção que toma como sendo o mesmo aquilo que é diferente. Desta forma, algo é tomado pelo que não é e vice-versa. Por fim, o comum da razão também está em que ela se afirma na autoevidência do indiferenciado, impedindo que ela mesma seja revelada de modo transparente. ${ }^{45}$ A razão comum desconhece a natureza do postulado lógico, pois o assume como um enunciado sobre coisas em si. Deste modo, ela confunde relações lógicas com relações ônticas, e confunde relações pertencentes a um conhecimento finito como relações dadas para um conhecimento absoluto. ${ }^{46}$ Em suma, a razão natural é comum, porque nivela diferenças essenciais, tornando-as comuns e impedindo-

\footnotetext{
42 Na análise do tópico apresentada em Sobre a Essência do Fundamento não está a elucidação da origem da ilusão transcendental (cf. GA 9, pp. 146-154).

Cf. GA 31, pp. 229-230.

Cf. Loparic, 1987, p. 586

Cf. GA 31, pp. 229, 232.

Cf. GA 31, pp. 234, 237.
} 
as de aparecer. Contudo, não é suficiente mostrar esta ordinariedade natural (natürliche Gemeinheit) na razão humana. É preciso mostrá-la de modo mais abrangente e originário como um momento essencial da finitude. ${ }^{47}$ Desta forma, questionando o que é propriamente a ordinariedade e porque ela pertence à razão natural, Heidegger pretende chegar ao estrato primitivo da ilusão transcendental.

A resposta a estas indagações surge da orientação indicada na interpretação das confusões presentes no uso comum do princípio da razão. Neste uso há uma confusão da diferença entre o lógico, o ôntico e o ontológico, e assim tudo é tomado indeterminadamente como 'ser'. Em uma nota de rodapé, Heidegger refere-se mais especificamente à indiferença (Indifferenz) e à indiferenciação (Unterschiesdlosigkeit) da compreensão de ser. ${ }^{48}$ A resposta é decisiva: o fundamento da ilusão transcendental reside numa característica estrutural da compreensão de ser. Ora, se a ilusão transcendental é um sinal da finitude da razão, e se as confusões originadas do traço comum da razão têm sua origem na compreensão de ser, então a finitude humana deve ser reconhecida na estrutura finita da compreensão de ser. Daqui também se segue que a finitude deve ser conceitualizada em domínios que se estendem para além da finitude no conhecimento.

A compreensão de ser está atuante, segundo Heidegger, não apenas nas proposições com as diferentes funções do verbo ser (predicativo, existencial e veritativo), mas em todo comportamento para com entes, fundando também a pessoalidade do ser humano. Na interpretação da compreensão de ser são destacadas oito características estruturais: 1) amplitude (todos os entes, totalidade do ente), 2) penetração em todos os tipos de comportamento humano, 3) inexpressividade, 4) esquecimento, 5) indiferenciação (Unterschiesdlosigkeit), 6) préconceitualidade (Vorbegrifflichkeit), 7) ausência de engano (Täuschungsfreiheit), 8) articulação inicial. ${ }^{49}$ A compreensão é essencial para o ser humano, de tal modo que:

Não estivesse no homem o compreender de ser, ele não poderia se comportar para consigo mesmo como ente, ele não poderia dizer 'eu' e 'tu', ele não poderia ser ele mesmo, não poderia ser pessoa. Ele seria impossível em sua essência. Portanto, a compreensão de ser é o fundamento da possibilidade da essência do homem. (GA 31, p. 125)

Em suma, a indiferenciação da compreensão de ser é a base explicativa do comum da razão humana. No contexto do comportamento cognitivo, em que a razão emprega de forma comum um postulado lógico, a indiferenciação da compreensão de ser é a origem de uma ilusão necessária. Segundo Heidegger, Kant não chegou a este limite explicativo, tendo permanecido na identificação crítica da ilusão atuante no princípio da razão. ${ }^{50}$ No entanto, o seu resultado é decisivo: a diferença entre fenômeno e coisa em si permite solucionar os problemas da razão e também conduz para a origem da ilusão. A confusão entre fenômeno e coisa em si é a estrutura geral da ilusão transcendental. Se a metafísica pertence à natureza humana, então também a peculiar confusão analisada por Kant. Deste modo, a confusão do realismo transcendental não é uma falha contingente da metafísica herdada, mas algo essencial. Ora, o que Heidegger vê na natureza humana, e que possibilita a confusão no princípio da razão e nas outras inferências dialéticas, é o modo de ser indiferenciado da compreensão de ser. Neste ponto, a interpretação se detém em perguntas que ficam sem resposta: de onde se origina e por que acontece a

\footnotetext{
Cf. GA 31, p. 236.

Cf. GA 31, p. 236 n5.

Cf. GA 31, pp. 41-44, 125.

Dahlstrom, 1987, p. 363, indicou sem desenvolvimento esta conexão entre a ilusão transcendental e a indiferenciação da compreensão de ser. Schalow elucida a origem da ilusão na inabilidade metafísica em diferenciar ser e ente (1987, p. 200). Não encontrei documentação para a hipótese de que a origem da metafísica se deve à prevalência da angústia na compreensão de ser (Schalow, 1987, p. 189). Esposito, 2004, p. 111 observou corretamente a relação entre a antitética da razão pura e a indiferença da compreensão de ser. Han-Pile, 2005, p. 97 não desenvolveu a hipótese de uma analogia entre a origem das ilusões dialéticas com a estrutura da Verfallen na compreensão de ser.
} 
indiferenciação na compreensão de ser? A indiferenciação é necessária ou admite ainda algum outro nível explicativo, ela admite um 'por que' adicional? Heidegger simplesmente afirma que é preciso iluminar a finitude para além da mera finitude do conhecimento humano. ${ }^{51}$

\section{A ilusão originária e "a mancha podre" na natureza humana}

As considerações precedentes são suficientes para compreender o alcance de uma afirmação de Heidegger em Davos, a propósito da não-verdade situada no ser-aí: “A não-verdade pertence ao núcleo mais íntimo da estrutura do ser-aí. E acredito ter descoberto aqui pela primeira vez a raiz onde está metafisicamente fundada a ‘ilusão’ metafísica de Kant.” (GA 3, p. 281). A ilusão transcendental tem sua raiz numa ilusão mais originária. A ilusão originária refere-se às indiferenciações derivadas da compreensão de ser. Ora, se a redução do primado da lógica implica a ampliação do conceito de verdade para além da verdade proposicional, então o mesmo também vale para o conceito de não verdade. Neste sentido, se a verdade originária está na transcendência que possibilita a abertura vinculada a entes, então a não verdade originária aparece em duas características da compreensão de ser: esquecimento e indiferenciação.

Contudo, Heidegger percebeu um problema na caracterização da compreensão de ser, pois as notas estruturais referidas pertencem à compreensão e não propriamente a ser. A despeito da íntima conexão entre ser e compreensão, o que é válido de ser também vale da compreensão de ser? Neste sentido, ele afirma que a articulação e a indiferenciação seriam características do próprio ser, e não apenas da compreensão de ser. ${ }^{52} \mathrm{~A}$ ilusão originária tem sua base não apenas na compreensão de ser, mas no próprio ser. Desta forma, a não-verdade originária poderia ser entendida como a finitude de ser, a pertinência mútua de ser e nada. Assim, a ilusão originária resultaria da finitude de ser, da ausência de todo "porquê" na relação entre ser e ente, na vincularidade (Verbindlichkeit) finita ao entes proporcionada pela compreensão de ser. Da ausência de um análogo da dedução transcendental dos sentidos de ser surgiriam as ilusões necessárias da infinitude. ${ }^{53}$

Deste modo, a ilusão da infinitude se estenderia para além das ilusões relativas ao princípio de razão suficiente, e as oito características da compreensão de ser permitiriam o desenvolvimento de uma tópica da ilusão originária. A liberdade, entendida primitivamente como vincularidade a entes (e não como causalidade), seria o lugar de ocorrência de ilusões originárias, e a formação de mundo também seria o palco de uma história exposta à ilusão originária. A série progressiva das condições, que Heidegger afirma como necessária para a compreensão da história, ${ }^{54}$ também portaria uma classe de ilusões. Assim sendo, a elucidação detalhada da ilusão originária permite uma nova tópica e a uma nova crítica, incorporando não apenas a ilusão transcendental, mas as ilusões nas vinculações não representacionais a entes. Naturalmente, a ilusão originária também acontece com os conceitos filosóficos, quando se mal compreende a sua sistematicidade e a sua natureza indicativo-formal. A conclusão metodológica de Heidegger é que toda a filosofia é vitima de uma ilusão, o que não implica a impossibilidade de uma saída relativa do engano originário. ${ }^{55}$

Estas hipóteses não podem ser elaboradas aqui. É importante ressaltar que Heidegger identificou na própria crítica kantiana a submissão a uma ilusão. Na doutrina da razão e na crítica das metafísicas transcendentes atuaria a ilusão originária. Kant pertence à tradição da metafísica grega recebida na visão de mundo cristã. Por exemplo, as representações greco-

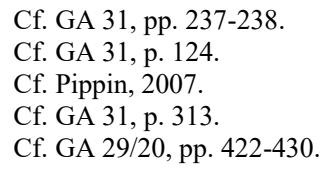


cristãs atuantes na metafísica criticada determinam o tratamento do conceito de liberdade a partir do conceito de causalidade. A diferença entre fenômeno e coisa em si, interpretada como a diferença entre conhecimento finito e infinito, incorpora o horizonte da compreensão dos entes como produzidos. Não menos importante é o primado da lógica na metafísica, que restringiu o horizonte de análise, e seria a base da arquitetônica na doutrina da razão. Heidegger pode afirmar inclusive que quanto mais seguro Kant procedeu no seu empreendimento crítico, tanto mais inseguros e indeterminados estavam os fundamentos de sua fundamentação da metafísica. ${ }^{56}$

Evidentemente, esta avaliação não é feita com a perspectiva de um retorno de uma metafísica transcendente ou da refutação das críticas kantianas. Talvez a conclusão geral seja que a ilusão dialética criticada por Kant não é única, mas aquela que resulta de uma tradição metafísica particular. Outras formas de ilusão e de crítica são possíveis. Em suma, a interpretação heideggeriana de Kant não se limita ao esquematismo e à temporalidade como tematizações não desenvolvidas da transcendência. O sentido positivo da Dialética Transcendental é a via que conduz a uma nova doutrina da ilusão, e não seria exagerado pretender que Heidegger entendesse parte de seu projeto como uma análise da ilusão originária. ${ }^{57}$

A título de conclusão apresentarei um problema relacionado com o sentido crítico da Dialética Transcendental. É muito conhecida a declaração kantiana de que a limitação da razão na metafísica representa uma perda apenas para as escolas, mas não atinge as posses e o interesse dos homens (B XXXII-XXXIII). O ganho positivo de uma metafísica depurada pela crítica é a possibilidade de uma ampliação da razão no domínio prático, atendendo ao interesse geral dos seres humanos. Ao final da Crítica, Kant afirma que, em razão dos fins essenciais que estão em jogo, sempre se retornará à metafísica como "se se tratasse de uma amada com a qual nos desaviéramos..." (B 878). Heidegger também emprega uma imagem ao expressar a resistência do entendimento comum àquela transformação no ser-aí que é exigida para uma compreensão não ilusória dos conceitos filosóficos. A comodidade natural do entendimento comum funda-se na "mancha podre" na natureza humana. Esta imagem foi usada Kant para designar o mal radical na natureza humana. ${ }^{58}$ É contingente a escolha dessa imagem do mal radical para indicar a força da ilusão originária nos conceitos filosóficos?

Além disso, na crítica à ilusão originária também haveria algo de positivo? A perda oriunda de uma crítica da ilusão radical afetaria a quem? No contexto da organização técnica das universidades é possível manter a distinção entre perdas para as escolas e preservação do interesse comum dos homens? ${ }^{59}$ Para finalizar, registro uma declaração de Heidegger acerca do propósito de mostrar a finitude originária do homem:

Não se trata de mostrar esta finitude para constatar que e onde estão os limites, onde se chega ao fim, onde termina, onde surge o não-mais-além, mas sim para despertar a tranquilidade interior (Gefasstheit) e o recolhimento (Sammlung) com e em que o essencial começa e persiste em seu tempo. (GA 31, p. 238)

Esta passagem sugere o significado não apenas teórico e negativo da crítica da ilusão originária. Pode-se dizer que ela aponta o inicio de uma jornada, na qual a crítica da ilusão originária conflui para uma tematização das instituições. Será um longo caminho de aprendizado

56 Cf. GA 31, pp. 205-206, 71-72, 246, sobre as críticas anteriores, cf. GA 27, p. 249, 257, 293, GA 3, pp. 6, 8-9, GA 36/37, pp. 3, 21-26.

57 Consideração o pensamento da história do ser, o transcendentalismo de Heidegger (Dahlstrom, 2005) precisaria ser investigado no tocante à crítica da ilusão transcendental.

58 Cf. Kant, RbV, Ak VI 38, GA 29/30, p. 423.

59 Cf. as referências de Heidegger ao problema do sentido da ciência formulado por Weber (GA 28, pp. 347-350). 
até a noção de Gelassenheit, no qual Heidegger precisará reconhecer a ilusão na própria noção de uma vontade de essência. ${ }^{60}$

\section{Referências}

DAHLSTROM, Daniel (2005), "Heidegger's Transcendentalism", Research in Phenomenology, vol. 35, pp. 29-54.

DAHLSTROM, Daniel (1991), "Heidegger's Kantian Turn: Notes to His Commentary on the "Kritik Der Reinen Vernunft"', The Review of Metaphysics, vol. 45, no. 2, pp. 329-361. Dahlstrom, Daniel (1989a), "Heidegger Kant-Kommentar, 1925-1936”, Philosophisches Jahrbuch, pp. 344-367.

DAHLSTROM, Daniel (1989b), “Heidegger's Kant-Courses at Marbourg, em Kisiel, Theodore \& Van Buren, John, Reading Heidegger from the Start, SUNY Press, New York, pp. 293308.

ESPOSITO, Constantino (2004), Kausalität als Freiheit: Heidegger liest Kant, Heidegger Studien, Vol. 20, pp. 101-125.

HAN-PILE, Béatrice (2005), "Early Heidegger's appropriation of Kant", em Dreyfus, Hubert and Wrathall, Mark, A Companion to Heidegger. Malden \& Blackwell Publishing, Oxford, pp. 173-189.

HEIDEGGER, Martin (GA 2), Sein und Zeit, Frankfurt, V. Klostermann Verlag, 1977.

HEIDEGGER, Martin (GA 3), Kant und das Problem der Metaphysik, Frankfurt, V. Klostermann Verlag, 1991.

HEIDEGGER, Martin (GA 9), Vom Wesen des Grundes, em Wegmarken, Frankfurt, V. Klostermann Verlag, 2a ed. Revisada, 1996.

HEIDEGGER, Martin (GA 21), Logik. Die Frage nach der Wahrheit, Frankfurt, V. Klostermann Verlag, 1976.

HEIDEGGER, Martin (GA 23), Geschichte der Philosophie von Thomas von Aquin bis Kant, Frankfurt, V. Klostermann Verlag, 2006.

HEIDEGGER, Martin (GA 24), Phänomenologische Interpretation von Kants Kritik der reinen Vernunft, 2a ed., Frankfurt, V. Klostermann Verlag, 1987.

HEIDEGGER, Martin (GA 25), Die Grundprobleme der Phänomenologie, 2a ed., Frankfurt, V. Klostermann Verlag, 1976.

HEIDEGGER, Martin (GA 27), Einleitung in die Philosophie, Frankfurt, V. Klostermann Verlag, 1996.

HEIDEGGER, Martin (GA 28), Der deutsche Idealismus (Fichte, Schelling, Hegel), Frankfurt, V. Klostermann Verlag, 1997.

HEIDEGGER, Martin (GA 29/30), Die Grundbegriffe der Metaphysik. Welt - Endlichkeit Einsamkeit, Frankfurt, V. Klostermann Verlag, 1983.

HEIDEGGER, Martin (GA 31), Vom Wesen der menschlichen Freiheit, Frankfurt, V. Klostermann Verlag, 2a ed. Revisada, 1994.

HEIDEGGER, Martin (GA 36/37), Sein und Wahrheit, Frankfurt, V. Klostermann Verlag, 2001.

60 Cf. GA 31, p. 303. 
JARAN, François (2010), "Toward a Metaphysical Freedom: Heidegger's Project of a Metaphysics of Dasein”, International Journal of Philosophical Studies, vol.18, no. 2, pp. 205- 227.

KANT, Immanuel (KrV), Kritik der reinen Vernunft, em Kants Werke Akademie Textausgabe Bd III, Walter de Gruyter, Berlin, 1968.

KANT, Immanuel, Die Religion innerhalb der Grenzen der blossen Vernunft, em Kants Werke Akademie Textausgabe Bd VI, Walter de Gruyter, Berlin.

LOPARIC, Zeljko (2009), "Kant: entre o ficcionalismo de Vaihinger e a fenomenologia de Heidegger", em M. Cepeda y R. Rango, Amistad y Alteridad. Homenaje a Carlos B. Gutiérrez, Ediciones Uniandes, Bogotá, pp. 503-521.

LOPARIC, Zeljko (1987), “Kant's Dialectic”, Noûs, vol. 21, no. 4, pp. 573-593.

MACANN, Christopher (1996), Heidegger's Kant Interpretation, em Critical Heidegger, Routledge, London/New York, pp. 97-120.

MÜLLER, Arnulf (2010), Weltanschauung - eine Herausforderung für Martin Heideggers Philosophiebegriff, Kohlhammer, Sttugart.

PIPPIN, Robert (2007), "Heidegger on Failed Meaning". Em S Crowell, e J. Malpas, Transcendental Heidegger, Stanford University Press, Stanford, pp. 199-214.

SCHALOW, Frank (1994), "The Unique Role of Logic in the Development of Heidegger's Dialogue with Kant", Journal of the History of Philosophy, vol. 32, no. 1, pp. 103-125.

SCHALOW, Frank (1987), "Re-opening the issue of World: Heidegger and Kant", Man and World, vol. 20, pp. 189-203.

SHEROVER, William (1971), Heidegger, Kant and Time, Indiana University Press, Bloomington and London. 